\title{
Transition from pediatric to adult renal services: a consensus statement by the International Society of Nephrology (ISN) and the International Pediatric Nephrology Association (IPNA)
}

\author{
Alan R. Watson - Paul Harden - Maria Ferris • \\ Peter G. Kerr • John Mahan • Maher Fouad Ramzy
}

Received: 26 May 2011 / Accepted: 2 June 2011 /Published online: 13 August 2011

(C) IPNA 2011

Keywords Adherence - Adolescene - Adult renal Pediatric · Transition · Youth work

The number of young patients graduating from paediatric to adult renal care has progressively increased due to improved management resulting in patient survival rates of $85-90 \%$ [1, 2]. Adult renal services are being exposed to an increasing number of adolescent and young adult patients who have either transitioned from paediatric care or presented directly to adult services. It is recognised that there are substantial risks of nonadherence at the time of transfer from pediatric to adult care and amongst the cohort of patients aged $<25$ managed in adult care [3, 4]. Recovery from acute kidney

This statement is also being published in Kidney International, Volume 80, Issue 7, October (1) 2011
A. R. Watson $(\bowtie)$
IPNA, UK,
Children's Renal \& Urology Unit,
Nottingham University Hospitals NHS Trust,
QMC Campus Derby Road,
Nottingham NG7 2UH, UK
e-mail: judith.hayes@nuh.nhs.uk
P. Harden
ISN, UK
M. Ferris $\cdot$ J. Mahan
IPNA, USA
P. G. Kerr
ISN, Australia
M. F. Ramzy
ISN, Eygpt

injury and increased detection of nephrourological problems on antenatal scanning means that there is also an increasing number of children with chronic kidney disease (CKD) stages 1-4 who are being followed by paediatric nephrologists $[5,6]$. There is general agreement that patients with CKD 3-4 should be transferred to adult services, whereas those with CKD 1-2 could most typically be followed in primary care with clear instructions to refer to nephrologists if there is evidence of progressive kidney damage and/ or hypertension or proteinuria. Growth and development are the essential issues for all children. For children with a chronic condition such as CKD, a comprehensive, multiprofessional team of clinicians, nurses, dietitians, social workers, play therapists, psychologists and educators is the most effective way to minimise disabilities and maximise the potential of each child. Support for children and families from a more diverse multiprofessional team is one of the major differences between paediatric and adult care [7].

While the most frequent aetiology of adolescent-onset CKD 5 is glomerular diseases, younger children more frequently develop CKD from congenital abnormalities (e.g. renal dysplasia, reflux-associated damage) along with hereditary conditions [8]. Adult nephrologists may be less familiar with these latter conditions. The difficulties of dealing with adolescent patients who have chronic illness superimposed upon all of the other physical, psychological and sexual changes of their development can make the management and transition issues for the patient, families and staff challenging $[9,10]$. The position paper from the Society for Adolescent Medicine in 1993 uses the term transition as a process that involves purposeful, planned efforts to prepare the paediatric patient to move from caregiver-directed care to disease selfmanagement in the adult unit [11]. In the most desirable 
format, therefore, transfer is an event that takes place at the end of a transition process designed to be a more purposeful and concerted effort to prepare the young person with a chronic condition to accept responsibility for his/her disease management $[7,12]$.

Renal units in different parts of the world have variable experiences and plans for transition and management of adolescents and young adults with CKD $3-5$. It is now recognised that the adolescent/young adult years embrace ages 14-24 years in terms of brain development and maturation. This may account for the increased risk-taking, impulsive behaviour and nonadherence issues so common in this age group [13, 14]. Approximately $25 \%$ of all teenagers and young adults with CKD 5 present primarily to adult services usually after the age of 16 years in many developed countries. In many developing countries, there are no paediatric renal units, and older children may well be looked after from the outset by adult nephrologists. Wherever managed, young people in the 14- to 24-year age group need special consideration, and it is important that their viewpoints are considered when transfer does take place between paediatric and adult units [15]. A number of these issues have been addressed at recent consensus meetings, particularly in the field of transplantation [16-18].

Although the authors in this document have experience in the area of health care transition (via research or clinical practice), there is minimal published evidence to validate many statements in this document. Rather, the content represents a consensus viewpoint on optimal clinical management developed by the panel via e-mail discussion and teleconference. The councils of both the International Society of Nephrology (ISN) and the International Pediatric Nephrology Association (IPNA) endorse this consensus statement describing the ideal care of young people with kidney disease during this critical phase of their lives. However, ISN and IPNA are global organisations and count among their members many nephrologists who practice in low-resource environments where it may be extremely challenging to achieve the standards of care described in this statement. It is anticipated that this statement will provide a basis for the development of locally appropriate recommendations for clinical practice.

\section{Consensus statement}

Where appropriate, components are marked with an A for essential and a D for desirable.

1. Transition to transfer

Transfer should occur from paediatric to adult nephrology services only after efforts to assess and prepare the adolescent/young adult have occurred and necessary patient care information has been delivered to the receiving adult service (A).

2. Transfer from pediatric to adult nephrology should:

a. be individualised for each patient after he/she has completed a transition plan; this will depend upon completion of physical growth and, where possible, educational, social and psychological attainment (A);

b. be agreed upon jointly by the patient and his/her family/carers in conjunction with the paediatric and adult renal care teams (A);

c. take place during a period without crises, especially if there is unstable social support (A);

d. take place after completing school education (A);

e. take into account treatment plans by other subspecialties, with particular reference to urological supervision $(\mathrm{A})$;

f. take place with due consideration of financial factors and not be done abruptly without adequate preparation as a result of financial pressures (A).

3. Transition process (Fig. 1)

The most effective time to transfer an adolescent/ young adult from a paediatric to adult renal service occurs after a transition process. Hence, young people should be:

a. introduced to the concept of transition in early adolescence (12-14 years) (A);

b. given information about transition in a gradual manner appropriate to his/her developmental stage and intellectual ability (A);

c. directed by identified lead clinicians (transition champions) in paediatric and adult units to coordinate and educate on transition issues (A);

d. assigned to a nominated key worker responsible for coordinating transition from both the paediatric and adult renal service (A); support professionals (nurses, youth workers, social workers etc) can be very effective in facilitating transition by providing access to ongoing support groups, providing practical aid and advice to the transitioning young person $[19,20]$;

e. provided with a generic transition plan that then can be individualised for each patient [21] (A); most transition plans have certain competencies to be achieved at a certain age (see example in Table 1).

Feedback from young people indicates that some like to follow a plan through different stages and some like to do it all in a short period prior to transfer [18];

f. include parents, other family members and even boyfriends/girlfriends (if the young person agrees), as more information lessens anxiety (A);

g. be offered the opportunity of an informal visit to the nominated adult service before transfer occurs (A); 
Fig. 1 Support for transition

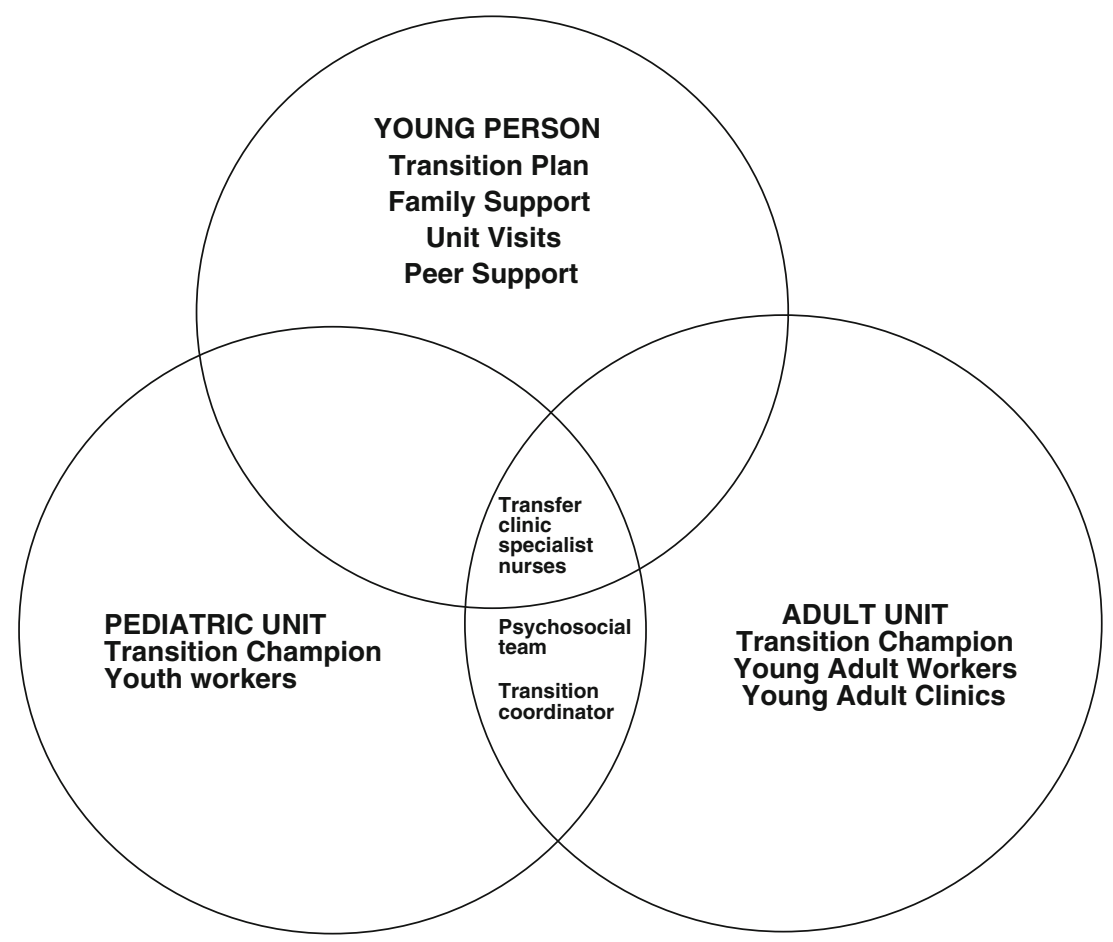

h. be given the opportunity to participate in group sessions with other young people who are about to transition for peer-support experience (A); peer support can be complemented by establishing a local e-mail and social networking group [18, 19];

i. be able to receive tools to aid in the acquisition of disease self-management skills, such as the transition medical passport, a self-administered transition, readiness survey and the $\mathrm{TR}_{\mathrm{x}}$ ANSITION Scale, which are useful adjuncts (D) [12] (see Appendix 1 for the $\mathrm{TR}_{\mathrm{x}} \mathrm{ANSITION}$ Scale).

The concepts of transition champions and transition coordinators deserve further delineation. A useful method to effectively develop a transition process for young people with CKD involves identifying specific transition champions: physicians in the paediatric and adult services who have special interest in organising and leading the transition process or programme for the young people in the area. These transition champions will be most effective when they are able to work closely with a designated transition coordinator (s) - typically a nurse, social worker or youth worker - who takes responsibility for coordinating the transition steps for the individual transitioning young people.

4. Transition or transfer clinic

a. a transfer clinic in either the adult or paediatric renal unit with both adult and paediatric nephrologist in attendance is the optimal minimum standard (A);

b. an internal medicine specialist or nephrologist in each adult service should take a special interest and be trained in managing young people with CKD 4-5 (D);
Table 1 Example of competencies expected of a young adult transferring to an adult renal unit
- I understand my condition and can describe it to others

- I know my medications and what they are for

- I can make decisions for myself about my treatment

- I know what the adult clinic arrangements are and who will be reviewing me in clinic

- I know how to make my appointments

- I can make my own transport arrangements to get to the hospital for appointments

- I know who to call in a medical emergency

- I am able to talk about my worries concerning blood tests and other treatments

- I know the dietary advice that I have to follow and the importance of activity

- I have appropriate knowledge about sexual health matters

- I have discussed alcohol, smoking and drug issues 
c. specialist nurses for adult patients who liaise with specialist nurses from the paediatric unit can ensure continuity of care (A);

d. transfer to adult renal care should include a comprehensive written and verbal summary of all the multidisciplinary aspects of the young person's care; this should include medical, nursing, dietary, social and educational information (A);

e. the young person should be prepared through a transition pathway to assert their autonomy and help provide the relevant information about themselves (A);

An ideal method to promote the successful transition of young people is through the use of a transition clinic where the adolescent/young adult is seen jointly by paediatric and adult specialists on a number of occasions before being transferred to adult renal services, preferably in a young adult clinic. However, tertiary paediatric renal units may refer to several adult services. Patient choice and the logistics of distance, numbers and cost make regular transition clinics less feasible.

\section{Continuity of care}

A recurring point raised by young people who have transferred is the lack of continuity of care and build up of trust that they experienced in the paediatric unit. It is appreciated that many transition issues raised in these statements are aspirational, but two options could be considered:

Option 1 An ideal method to promote successful transition is to preserve continuity of care through the efforts of a small team of specific professionals responsible for assuring the care of the transferred young person. This may involve an adult nephrologist, nurse specialist and one or more support staff (youth worker, social worker, etc) in the adult service. This dedicated team should have training in managing teenagers and young adults and have knowledge of paediatric renal diseases (D). The potential availability of such a team will vary according to country and facilities resourced.

Option 2 Adult renal centres could establish youngadult clinics that would incorporate both patients transferred from paediatric care and adolescents and young adults (aged <24) who may have presented with CKD 4-5 directly to the adult renal unit (D) [22].

A recent survey of US internists found that many felt the need for better training in congenital and childhood-onset conditions, and expressed concerns about psychosocial and financial issues [23]. Training of junior doctors on transition issues needs to be included in the training of adult specialists $[24,25]$ (D). This training is more imperative for lead clinicians in the adult centre.

\section{Conclusions}

Transition from paediatric to adult renal services is an individualised process that provides the young person with appropriate self-management skills and assesses support structures. As young people are in transition from 14 to 24 years, it is vital that there is good communication between paediatric and adult services, especially at the point of transfer. Support for this age group should be developed on both paediatric- and adult-focused sides. The consensus statements highlight developments that are necessary to ensure a successful health care transition process.

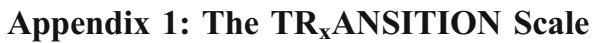

The Transition Scale is a mechanism to assess and monitor progress in achieving the goals of transition: the ability for the adolescent/young adult to provide her/his own selfmanagement and not be reliant on parental care.

The components include:

Type (of illness)

Rx

Adherence

Nutrition

Self-management skills

Informed reproductive health

Trade/school

Insurance

Ongoing support

New health care providers

The score is determined by a professional member of the renal unit who designates for the young person a subscore of $0-1(0=$ no ability, $0.5=$ partial ability, $1=$ desired ability $)$ for each component. The total score can be used to monitor progress over time, and the subscores can be used to identify gaps that need to be addressed.

\section{References}

1. Lewis MA, Shaw J, Sinha M, Adalat S, Hussain F, Inward C (2008) Demography of the UK pediatric renal replacement therapy population. UK Renal Registry Report. UK Renal Registry, Bristol UK: Chap 13; pp 257-267 
2. Ferris ME, Gipson DS, Kimmel PL, Eggers PW (2006) Trends in treatment and outcomes of survival of adolescents initiating endstage renal disease care in the United States of America. Pediatr Nephrol 21:1020-1026

3. Watson AR (2000) Non-compliance and transfer from pediatric to adult transplant unit. Pediatr Nephrol 14:469-472

4. Dobbels F, Ruppar T, De Geest S, Decorte A, Van DammeLombaerts R, Fine RN (2010) Adherence to the immunosuppressive regimen in pediatric kidney transplant recipients: a systematic review. Pediatr Transplant 14:603-613

5. Watson AR, Phillips D, Argles J (1996) Transferring adolescents from paediatric to adult renal units. Br J Ren Med 1:24-66

6. Cameron JS (2001) The continued care of children with renal disease into adult life. Pediatr Nephrol 16:680-685

7. Watson AR (2005) Problems and pitfalls of transition from paediatric to adult renal care. Pediatr Nephrol 20:113-117

8. Ferris ME, Mahan JD (2009) Pediatric chronic kidney disease and the process of health care transition. Semin Nephrol 29:435-444

9. Viner RM (2008) Transition of care from pediatric to adult services: one part of improved health services for adolescents. Arch Dis Child 98:160-163

10. Betz CL (2010) Approaches to transition in other chronic illnesses and conditions. Pediatr Clin North Am 57:983-996

11. Blum RW, Garell D, Hodgman CH, Jorissen TW, Okinow NA, Orr DP, Slap GB (1993) Transition from child-centered to adult healthcare systems for adolescents with chronic conditions. A position paper of the Society for Adolescent Medicine. J Adolesc Health $14: 570-576$

12. Ferris ME, Wood D, Ferris MT, Sim P, Kelly B, Saidi A, Bhagat S, Bickford K, Jurczyk I (2011) Toward evidence-based health care transition: The Health Care Transition Research Consortium. Int J Child Adolesc Health 3:479-486

13. Durston S, Casey BJ (2005) What have we learned about cognitive development from neuroimaging? Neuropsychologia 44:2149-2157

14. Giedd JN (2008) The teen brain: Insights from neuroimaging. J Adoles Health 42:335-343
15. Bell L (2007) Adolescents with renal disease in an adult world: meeting the challenge of transition of care. Nephrol Dial Transplant 22:988-991

16. Bell LE, Bartosh SM, Davis CL, Dobbels F, Al-Uzri A, Lotstein D, Reiss J, Dharnidharka VR (2008) Adolescent transition to adult care in solid organ transplantation: a consensus conference report. Am J Transplant 8:2230-2242

17. British Association for Pediatric Nephrology (BAPN) Renal Association (2009) Helping adolescents and young adults with end stage renal failure. http://www.bapn.org/clinical-standards. html. accessed Aug 2010

18. Webb N, Harden P, Lewis C, Tizzard S, Walsh G, Wray J, Watson A (2010) Building consensus on transition of transplant patients from pediatric to adult healthcare. Arch Dis Child 95:606-611

19. Watson AR (2009) Helping adolescent transition into adult care. Br J Ren Med 14(suppl):34-35

20. Watson AR, Hilton D, Hackett D (2010) Therapeutic recreation camps to provide a residential experience for young people in transition to adult renal units. Pediatr Nephrol 25:787-788

21. The Royal Children's Hospital, Melbourne. What is adolescent transition? www.rch.org.au/transition Accessed 26.1.11

22. Bent N, Tennant A, Swift T, Posnett J, Scuffham P (2002) Chamberlain MA (2002) Team approach versus ad hoc health services for young people with physical disabilities: A retrospective cohort study. Lancet 360:1280-1286

23. Peter NG, Forke CM, Ginsburg KR, Schwarz DF (2009) Transition from pediatric to adult care: internists' perceptives. Pediatr 123:417-423

24. Patel MS, O'Hare K (2010) Residency training in transition of youth with childhood-onset chronic disease. Pediatr 126:S190 S193

25. Barendse RM, aan de Kerk DJ, Kindermann A, Fishman LN, Grand RJ, Bartelsman JF, Heymans HAS (2011) Transition of adolescents with inflammatory bowel disease from pediatric to adult care: A survey of Dutch adult gastroenterologists' perspectives. Int J Child Adolesc Health 3:609-616 